\title{
Sexual Risk Behavior Changes Among HIV+ and HIV - Female Injecting Drug Users Over 4 Years
}

Curtis Dolezal PhD , Anke A. Ehrhardt PhD , Heino F.L. Meyer-Bahlburg Dr. and Rer. and Nat. , Xinhua Liu PhD , Theresa M. Exner PhD , Judith G. Rabkin PhD , Jack M. Gorman MD , Karen Marder MD and MPH \& Yaakov Stern PhD

To cite this article: Curtis Dolezal PhD , Anke A. Ehrhardt PhD , Heino F.L. Meyer-Bahlburg Dr. and Rer. and Nat. , Xinhua Liu PhD , Theresa M. Exner PhD , Judith G. Rabkin PhD , Jack M. Gorman MD , Karen Marder MD and MPH \& Yaakov Stern PhD (1998) Sexual Risk Behavior Changes Among HIV+ and HIV - Female Injecting Drug Users Over 4 Years, Women \& Health, 27:4, 1-17, DOI: 10.1300/J013v27n04_01

To link to this article: https://doi.org/10.1300/J013v27n04_01

曲 Published online: 21 Oct 2008.

Submit your article to this journal $\pi$

ЏII Article views: 52

Q View related articles $\sqsubset$

4 Citing articles: 1 View citing articles 


\title{
Sexual Risk Behavior Changes Among HIV+ and HIV - Female Injecting Drug Users Over 4 Years
}

\author{
Curtis Dolezal, PhD \\ Anke A. Ehrhardt, PhD \\ Heino F. L. Meyer-Bahlburg, Dr. Rer. Nat. \\ Xinhua Liu, PhD \\ Theresa M. Exner, PhD \\ Judith G. Rabkin, PhD \\ Jack M. Gorman, MD \\ Karen Marder, MD, MPH \\ Yaakov Stern, PhD
}

\begin{abstract}
This paper examines the sexual risk behavior of female injecting drug users who participated in a 4 year longitudinal
\end{abstract}

Curtis Dolezal, Anke A. Ehrhardt, Heino F. L. Meyer-Bahlburg, Theresa M. Exner, Judith G. Rabkin, Jack M. Gorman, Karen Marder, and Yaakov Stern are affiliated with the HIV Center for Clinical and Behavioral Studies, and Xinhua Liu is affiliated with the Department of Biostatistics, New York State Psychiatric Institute and Columbia University, New York, NY.

The authors wish to thank the women who agreed to participate in this study. They also wish to thank Robert Kertzner, MD, for his input regarding the selection of medical symptoms and Dinah Gay for library assistance.

This research was supported by center grants 5-P50-MH43520 from NIMH/ NIDA and 2-P50-MH43520, Anke A. Ehrhardt, Principal Investigator, and MH-30906 from NIMH.

Some of the results of this study were presented at the 21st Annual Meeting of the International Academy of Sex Research, Provincetown, MA, 1995.

Address correspondence to: Heino F. L. Meyer-Bahlburg, New York State Psychiatric Institute, 722 West 168th Street, Unit $\# 10$, New York, NY 10032 (E-mail: MEYERB@CHILD.CPMC.COLUMBIA.EDU.)

Women \& Health, Vol. 27(4) 1998

(C) 1998 by The Haworth Press, Inc. All rights reserved. 
study. Both HIV + and HIV - women showed increases in monogamy, decreases in the frequency of unprotected vaginal/anal sex, and decreases in a risk index score throughout the study. HIV + women had fewer occasions of unprotected sex than HIV - . However, a substantial proportion of the sample continued to engage in unprotected sex. Among the HIV+ women, depressed mood was significantly related to abstinence and to fewer occasions of unprotected sex, but CD4, medical symptoms, neurological impairment, and memory test performance were not associated with sexual risk behavior. [Article copies available for a fee from The Haworth Document Delivery Service: 1-800-342-9678. E-mail address: getinfo@haworth pressinc.com]

Female injecting drug users (IDUs) face multiple challenges with the advent of the AIDS epidemic. They are vulnerable to HIV infection via two major transmission routes: sexual intercourse and needle-use practices. While this is true also of male IDUs, there are several reasons why IDU women are at even greater risk with regard to their sexual behavior than IDU men. For HIV, male-to-female sexual transmission is more than twice as efficient as that of female-to-male (Nicolosi et al., 1994). Female IDUs are also more likely than male IDUs to exchange sex for money or drugs and to have an IDU sex partner (Davies, Dominy, Peters, \& Richardson, 1996; Booth, 1995; Booth, Koester, \& Pinto, 1995; Freeman, Rodriguez, \& French, 1994; Dwyer et al., 1994). Furthermore, it has been suggested that factors such as poverty, addiction, poor self-image, low self-efficacy, and the threat of domestic violence affect women's ability to reduce drug and sex risk behaviors (Weissman \& Brown, 1995; O'Leary \& Jemmott, 1995).

The current study focuses on sexual risk behavior in a cohort of HIV+ and HIV - female IDUs who participated in a longitudinal natural history study of HIV disease progression in New York City. When the study began in 1988, women comprised nearly a quarter of the city's AIDS cases, and $60 \%$ of all women diagnosed with AIDS that year were classified as IDUs (New York City Department of Health, 1988). Estimates of HIV seroprevalence in New York City at the time showed very high rates (typically over $50 \%$ ) among male and female IDUs (Battjes, R. J. \& Pickens, R., 1988; Kleinman, P. H., Friedman, S. R., Goldsmith, D. S., Mauge, C. E., \& Des Jarlais, D. C., 1988; Schoenbaum, E. E., Selwyn, P. A., Hartel, D., \& Friedland, G. H., 1988). 
SEXUAL RISK BEHAVIOR REDUCTION AMONG FEMALE IDUS

In a summary of intervention studies among IDUs, Des Jarlais, Friedman, Choopanya, Vanichseni, and Ward (1992) note changes in injection risk behavior were greater than changes in sexual risk behavior in studiès that compared the two. Nevertheless, several studies show that IDUs have reduced their sexual risk behavior (Rietmeijer et al., 1996; Iguchi et al., 1996; Deren et al., 1995; Des Jarlais et al., 1995; Booth \& Waters, 1994; Des Jarlais et al., 1992; Fisher \& Fisher, 1992). The vast majority of these assess the effectiveness of risk reduction intervention programs. Although these interventions typically combine men and women, and do not report results separately by gender, Exner, Seal, and Ehrhardt (1997) summarized a number of intervention studies specifically involving women, several of which demonstrated the capacity of IDU women to change their behavior in response to interventions.

Even in the absence of participation in a formal HIV intervention, several factors would be expected to affect risk reduction: increased exposure to AIDS-related information (Wolitski, Fishbein, Johnson, Schnell, \& Esacove, 1996), the influence of participation in an AIDS study, even when not in an intervention (Deren et al., 1995, and Iguchi et al., 1996, found reductions in sexual risk behavior for control participants, as well as those in intervention/treatment, resulting in no treatment effect), and acquaintances and/or partners becoming infected with HIV or lost due to AIDS-related deaths (Schilling, El-Bassel, \& Gilbert, 1993).

\section{SEXUAL RISK BEHAVIOR AS A FUNCTION OF HIV STATUS AND HIV-DISEASE PROGRESSION}

HIV + IDUs have reported lower levels of sexual risk behavior than HIV - IDUs, although men and women are typically combined in these studies (Friedman et al., 1994; Vanichseni et al., 1993). Watkins et al. (1993), however, analyzed for gender differences a sample of IDUs in Philadelphia that was 23\% female and found a main effect for HIV status as a predictor of condom use, and there was no significant gender by serostatus interaction.

Although there is some indication that HIV-positive IDUs (after seroconversion) practice safer sexual behavior than HIV-negative comparison IDUs, the relationship between HIV-disease progression and sexual risk behavior is largely an unexplored issue. Various indicators of disease progression have been investigated in the same sample of IDU women 
included in the current manuscript. Compared to the HIV - , these HIV+ women had lower CD4 counts, more medical symptoms (El-Sadr et al., 1992), more neurological impairment, and poorer neuropsychological performance (Stern et al., 1996; Marder et al., 1995). These HIV+ and HIV women did not differ in depressive symptoms, although both groups reported more depressive symptoms than found in general population samples (Rabkin et al., 1997; Lipsitz et al., 1994). Although depressive symptoms were not associated with HIV status, among the HIV+ women, those with fewer symptoms showed more psychological improvement over time than those with more symptoms (Rabkin et al., 1997).

Although it seems reasonable to hypothesize that increased illness and HIV-related symptoms would lead to reductions in sexual behavior, very little is known about how the potential effects of HIV disease relate to continued sexual risk behavior. The current study was part of a larger project that also included cohorts of IDU and gay men. Some indicators of sexual risk behavior were associated with CD4, medical symptoms, and neuropsychological performance among the IDU men (Dolezal et al., 1997) and CD4 and medical symptoms among the gay men (Exner et al., 1997). However, the generalizability of these findings to women is debatable.

Some studies by others have looked at the association between depressive mood and sexual behavior among IDUs but the findings are inconsistent. Nemoto et al. (1991) reported that IDU women who had higher numbers of sex partners were more likely to have depressive symptoms. However, Schilling et al. (1993) found that female IDUs who had more depressive symptoms were more likely to report behavior change to reduce their risk for HIV infection. Multiple partners may be more common among women who are not in a primary relationship, and thereby may be related to loneliness and depression. It may also be that higher levels of risk lead to greater feelings of vulnerability and depression but these feelings may actually result in efforts to reduce sexual risk behavior.

The current study assessed changes in sexual risk behavior over a 4-year period among IDU women as a function of time and HIV status. Based on the information presented above, we expected to find reductions in sexual risk behavior over time with lower levels of risk among the HIV+ women. In addition, exploratory analyses assessed the association between sexual risk behavior and immunological, medical, neurological, neuropsychological, and psychiatric indicators of disease progression. This study fills a gap in the current literature as a longitudinal study assessing whether there are reductions in sexual risk behavior that are maintained over time among IDU women not in a risk-reduction program, 
and whether sexual risk behavior is associated with disease progression among HIV+ women.

\section{METHOD}

\section{Sample}

The current analyses are based on data from a comprehensive natural history study of HIV disease in New York City. An evaluation of sexual risk behavior in this cohort at baseline has been reported previously (Ehrhardt et al., 1995).

Women were recruited via advertisements, referrals, and word of mouth. All participants were required to have known their HIV status for at least 6 months prior to study entry and, if HIV+, they could not meet CDC criteria for AIDS (Centers for Disease Control, 1986). Other eligibility criteria for the IDU women differed slightly between two recruitment sites. Participants recruited through various clinics at Harlem Hospital, advertisements in Harlem, and referrals (two-thirds of the sample) had to have used intravenous drugs at least 10 times since 1982 and at least once in the previous year. Eligibility requirements for those recruited through a methadone clinic at Roosevelt Hospital included attendance at the methadone maintenance program for at least 3 months, and the use of intravenous drugs at least 10 times since 1982 but not necessarily in the previous 12 months.

Participants were paid $\$ 10$ per hour for their participation and were seen every 6 months for up to 8 visits. Since psychosexual assessments at baseline inquired about the preceding 6 months, assessments potentially covered a 4-year period. Blood assays at each 6-month assessment included HIV antibody tests by the Retrovirology Laboratory of the New York City Department of Health.

\section{Assessment}

Sexual risk behavior was assessed by interview using the Sexual Risk Behavior Assessment Schedule, Adult, IDU Women (SERBAS-A-DF; Meyer-Bahlburg, Ehrhardt, Exner, Calderwood, \& Gruen, 1988). Interviewers were masters-level clinicians who were trained according to a standard protocol (Gruen \& Meyer-Bahlburg, 1992) and were systematically monitored throughout the study in order to avoid interviewer drift. Participants were assigned to interviewers by interviewer availability, i.e., 
their interviewers varied over the course of the study. Although a number of sex-related variables are reported below for descriptive purposes, our primary longitudinal analyses included four indicators of sexual risk: (a) abstinence, (b) monogamy, (c) frequency of unprotected peno-vaginal and/or peno-anal sex, and (d) a risk index. Same-sex partners were included in our definition of abstinence (having no male or female sex partner) and monogamy (having only one sex partner, whether male or female, and regardless of whether the partner was monogamous). The frequency of unprotected vaginal and/or anal sex variable was categorized as follows: $0=$ no unprotected occasions, $1=$ once a month or less, $2=$ two-three times per month, $3=$ once a week, $4=$ twice a week, $5=$ three times per week, $6=$ four-six times per week, $7=$ daily or more. The risk index is a modification of indices used and validated against seroconversion rates in the Chicago MACS study (Joseph et al., 1987; Ostrow, 1989). Categories are: $0=$ abstinent; $1=$ monogamous and uses a condom for each occasion of vaginal and/or anal sex or does not engage in vaginal/anal sex; OR non-monogamous but does not engage in vaginal/anal sex; $2=$ monogamous and has unprotected vaginal or anal sex, OR non-monogamous and uses a condom for each occasion of vaginal and/or anal sex; $3=$ non-monogamous and has unprotected vaginal or anal sex.

At the beginning of the study, 21 additional IDUs (16 men and 5 women) were recruited to take part in a test-retest SERBAS reliability study. Acceptable reliability was found for abstinence (100\% test-retest agreement), monogamy (kappa $=80)$, the frequency of unprotected sex $(\mathrm{r}=$ $.78)$, and the risk index score $(r=.92)$.

CD4 count was categorized as above 500, 200-500, and below 200. Medical histories and exams were conducted at every visit and $8 \mathrm{HIV}$-related symptoms or diagnoses were selected based on the assumption that they would cause particular discomfort and possibly reduce the likelihood of engaging in sexual activity. These were pneumonia, diarrhea, night sweats, fever, meningitis, severe weight loss (10\% in last 3 months), shortness of breath, and persistent cough. Symptom totals were categorized as no symptoms, 1 symptom, and 2 or more symptoms. Several neurological functions were assessed through neurological exams. The examining neurologist then classified the participant using a 10-point modified Kurtzke disability status scale (Kurtzke, 1983). As in Stern et al. (1996) and Marder et al. (1995) we have included the Kurtzke as a dichotomous score where $0=$ minimal or no disability, and $1=$ moderate to severe disability ( 3 or more on the original 10 -point scale). The neuropsychological test chosen for our analyses was the Selective Reminding Test (Buschke \& Fuld, 1974), a memory test. This test was selected since 
memory was the neuropsychological domain most associated with low CD4 in a published report on our cohort (Stern et al., 1996). Since there is typically a learning effect over time for such memory tests, this effect was minimized by using a residual score, the difference between the actual test score and a score estimated based on age, education, and time from baseline, with coefficients coming from the HIV-negative participants, a "nonclinical" sample. Finally, the SCL-90 subscale Depression (Symptom Check List; Derogatis, Lipman, \& Covil, 1973) was included in analyses as a continuous variable (not administered at visit 8 ).

\section{Data Analysis}

Analyses of the longitudinal data were performed by applying generalized estimating equations (GEE) to regression analyses with repeated measures. The statistical method (Liang \& Zeger, 1986) takes into account the multiple visits per subject and the fact that the repeated measures from a single individual over time are likely to be correlated with one another. This method allows for missing data (a distinct advantage given the attrition in our sample). It uses all available data from all participants, and the repeated measures for each subject (up to 8 visits per variable) are treated as a cluster. Visits with low participant numbers simply contributed less to the overall results than visits involving high participant numbers. For the binary outcome variables, abstinence and monogamy, logistic regression analyses were used that provide estimates of the odds-ratios. Linear regression was applied to the analyses involving the risk index. The categorized variable, frequency of unprotected sex, had a skewed distribution, and exponential regression was used for these analyses. The mean of this dependent variable is linked to independent variables through a logarith. mic transformation so that the regression coefficient indicates the relative change in the log-transformed mean score for a unit change in the independent variables. A formulaic expression of this regression would be: $\log (\operatorname{mean}(\mathrm{Y}))=\operatorname{linear}$ combination of independent variables.

In the initial analyses involving the entire sample, our models were primarily designed to test for risk behavior changes over time (years since baseline), the effect of HIV status, and HIV status by time interactions, i.e., differences in rates of change over time between HIV+ and HIV women. Baseline age and education were initially included in all models but were dropped (as was the HIV status by time interaction) if they did not show at least a statistical trend $(p<.10)$ toward an association with the dependent variable.

Subsequent analyses were limited to HIV+ participants and assessed the relationship between sexual risk behavior and indicators of disease 
progression. Since there are many possible non-medical reasons why changes would occur over time, including increasing exposure to HIV/ AIDS information, time was included as a surrogate for such non-medical effects.

\section{RESULTS}

\section{Sample Description}

Of the 76 women enrolled in the study, four seroconverted in the course of the study and were excluded from these analyses, resulting in a sample of $39 \mathrm{HIV}+$ and $33 \mathrm{HIV}$ - women. The sample was $65 \%$ Black, $18 \%$ White, and $17 \%$ Latina. Their mean age at baseline psychosexual assessment was 37.1 (range $=24-55$ ). The women had an average of 11.5 years of education. Half of the sample (51\%) had never been married while $14 \%$ were married and living with their spouse. All of the women reported alcohol use, $82 \%$ reported injecting drugs, and 96\% reported other (noninjected) drug use at some point in the study. The average age for first injection was 22 (range 13-37). HIV+ and HIV - women did not differ in these demographic and drug use variables with the exception of a trend for HIV+ women to have more education $(t=-1.79 ; p=.077)$.

Seven women did not have a sexual partner during the time they participated in the study. Eight women reported having a female sex partner (one exclusively). Of the sexually active, all but one woman had vaginal sex (the one who did not have a male partner), 20\% engaged in anal sex, $95 \%$ reported having a spouse/lover/steady partner, and $51 \%$ had a "one-nightstand" at some point in the study. HIV + and HIV - women did not significantly differ on any of these variables. However, among the sexually active, all of the HIV - and $85 \%$ of the HIV+ women reported having unprotected vaginal or anal sex at some point in the study, a statistically significant difference.

Women from the two recruitment sites did not differ at baseline on age, education, HIV serostatus, rates of monogamy, or frequency of unprotected sex. The women recruited from the methadone clinic at Roosevelt Hospital had higher rates of abstinence and therefore lower risk index scores, but subsequent analyses (not shown) found no differences in rates of change on any of our sexual risk variables between women from the two recruitment sites.

In addition to the fact that we began with a relatively small sample, attrition was a major concern. Slightly less than two-thirds of the baseline 
sample participated in Visit 7. Data collection was stopped early during Visit 8 after only 16 women were interviewed. However, Visit 8 was included in our analyses in order to utilize all available data and to maximize the number of observations available since the sample size was small. Deaths account for only a portion of the attrition (of 11 recorded deaths by Visit 8,6 were confirmed AIDS-related and 2 occurred in HIV - women). We compared those who remained in the study at Visit 7 with the rest of the sample on their baseline assessments of demographics, sexual risk behavior, and indicators of disease progression (not shown). The women in the study at Visit 7 had higher levels of education and lower Depression subscale scores than the rest of the sample. They also showed a statistical trend $(p<.10)$ toward higher memory scores and higher CD4 counts at baseline.

\section{Sexual Risk Behavior as a Function of Time and HIV Status}

Trends in the sexual risk behavior of the HIV + and HIV - IDU women are shown in Figure 1. Since few women contributed data tor Visit 8, the apparent increase in risk behavior for the HIV - women between Visits 7 and 8 does not contribute much to statistical tests for time trends.

Table 1 shows the results of analyses assessing time trends and HIV-status differences. There was a trend for younger and less educated women to have more occasions of unprotected sex. These modest effects were not seen when both age and education were included in the model; therefore, education was included alone in the final model. Parallel models including age instead of education produced comparable results (not shown). Age and education are not associated with any of the other dependent variables.

HIV + women did not differ from HIV - women in terms of abstinence or monogamy, but HIV+ women had fewer occasions of unprotected sex and were lower on the risk index score (marginally significant). There were increases in rates of monogamy and declines in the risk index score and the frequency of unprotected sex for both HIV+ and HIV - women but no changes over time in the rates of abstinence.

\section{Sexual Risk Behavior as a Function of Disease Progression Among HIV+ Women}

At baseline slightly over one fifth of the HIV + women had CD4 counts below 200, and a third of the sample were above 500; $40 \%$ did not have any of the selected symptoms while $40 \%$ had 2 or more; a third of the sample were classified with moderate to severe neurological disability; 
FIGURE 1. Sexual Risk Behavior Over Time Among HIV+ and HIV - IDU Women

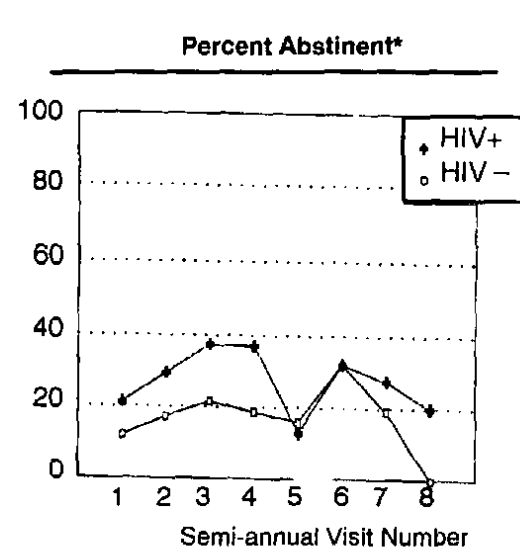

${ }^{\star}$ Abstinent $=$ no female or male sex partners in previous 6 months.

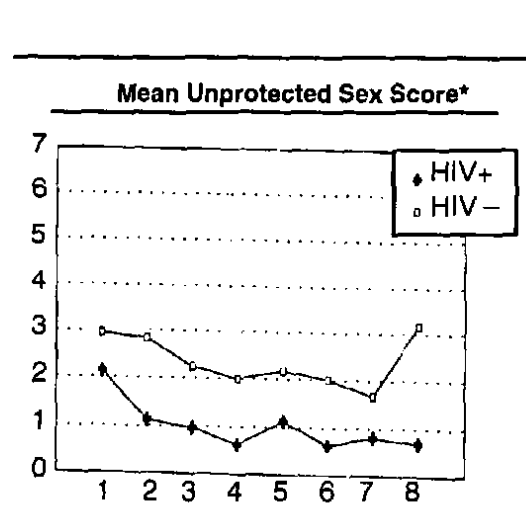

Semi-annual Visit Number

*Unprotected Sex Score is based on frequency. of unprotected anal or vaginal sex with male sex partners in previous 6 months. Score ranges from $0=$ no unprotected sex to $7=$ unprotected sex daily or more often ( $3=$ once a week).

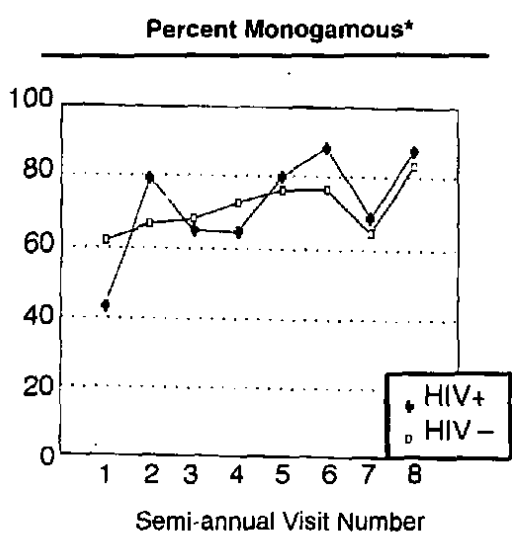

*Monogamous = reports 1 sexual partner (male or female) in the previous 6 months. Includes all participants sexually active at the given visit.

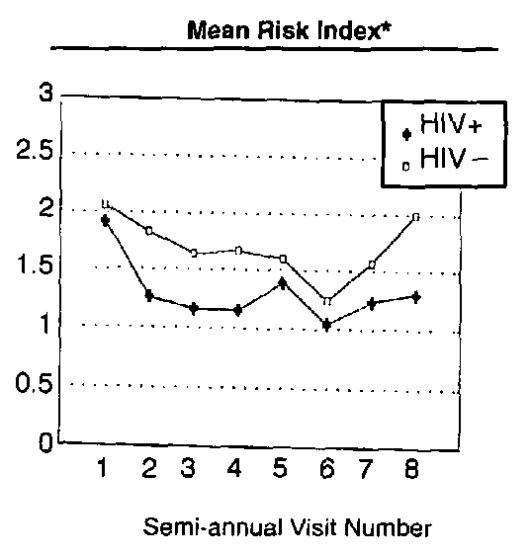

${ }^{\star}$ Risk Index ranges from $0=$ abstinence to 3 = multiple partners (male or female) and unprotected vaginal and/or anal sex in the previous 6 months 
TABLE 1. HIV Status Effects and Time Trends in Sexual Risk Behavior Among Female IDUs $(\mathrm{N}=72)$

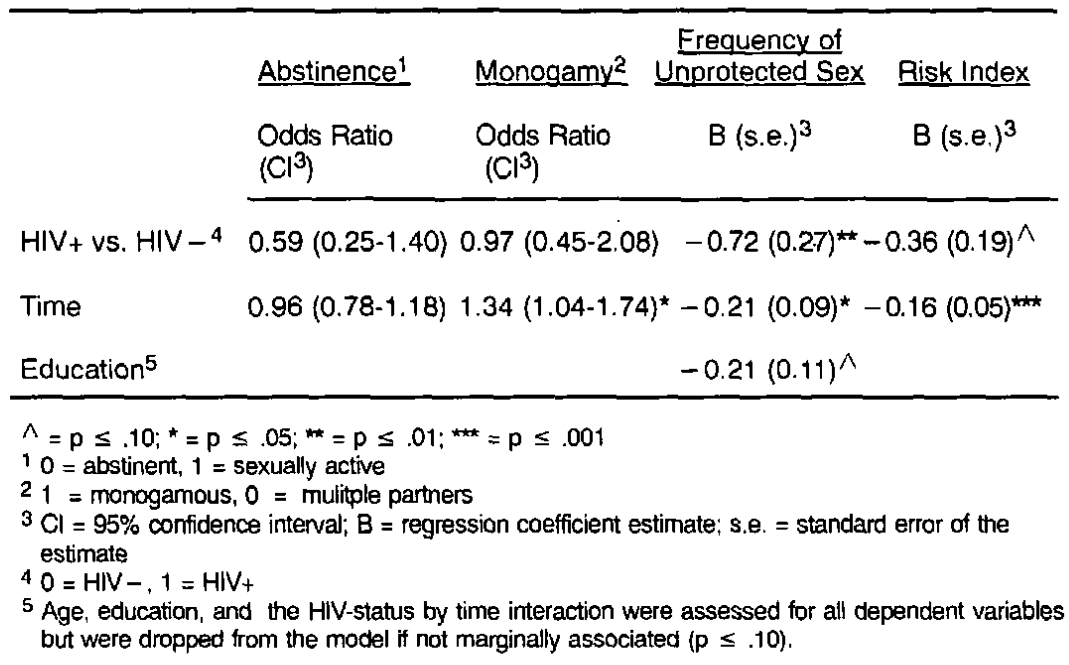

mean scores (and SDs) were 52.5 (8.4) for the Selective Reminding TestTotal Recall, and $1.7(0.9)$ for the SCL-90 subscale Depression. The associations between these indicators of disease progression and sexual risk behavior are reported in Table 2. CD4, medical symptoms, Kurtzke neurological assessment, and the Selective Reminding Test were not related to any of the sexual risk behavior variables. Higher levels of depressive symptoms were associated with higher rates of abstinence and lower frequencies of unprotected sex. These associations were maintained when controlling for CD4 or medical symptoms in separate analyses (not shown).

\section{DISCUSSION}

There were encouraging decreases in sexual risk behavior throughout the assessment period. However, it is important to note that a substantial amount of risk behavior continued, with $83 \%$ of the total sample reporting unprotected vaginal or anal sex at some point in the study. Differences between HIV - and HIV+ women, when found, were in the expected direction of lower risk among the HIV+. 
TABLE 2. The Association Between Sexual Risk Behavior and Indicators of HIV Disease Progression Among HIV+ IDU Women $(\mathrm{N}=39)$

\begin{tabular}{|c|c|c|c|c|}
\hline & $\begin{array}{l}\text { Abstinence } 1 \\
\text { Odds Ratio } \\
\left.(\mathrm{Cl})^{3}\right)\end{array}$ & $\begin{array}{l}\text { Monogamy } \\
\text { Odds Ratio } \\
\left.(\mathrm{Cl})^{3}\right)\end{array}$ & $\frac{\begin{array}{c}\text { Erequency of } \\
\text { Unprotected Sex }\end{array}}{B(\text { s.e. })^{3}}$ & $\begin{array}{c}\text { Risk Index } \\
\mathrm{B}(\mathrm{s} . e .)^{3}\end{array}$ \\
\hline \multicolumn{5}{|l|}{ 1. $\mathrm{CD} 4$} \\
\hline $\mathrm{CD} 4>500$ & 1 & 1 & & \\
\hline CD4 200-500 & $1.45(0.51-4.11)$ & $1.11(0.42-2.92)$ & $0.23(0.37)$ & $0.02(0.26)$ \\
\hline CD4 $<200$ & $0.27(0.07 \cdot 1.10)$ & $0.92(0.29-2.93)$ & $0.08(0.43)$ & $-0.46(0.33)$ \\
\hline Time & $1.12(0.82-1.54)$ & $1.54(1.00-2.39)^{\star}$ & $\star-0.27(0.15)^{\wedge}$ & $-0.14(0.07)^{\wedge}$ \\
\hline $\mathrm{Age}^{4}$ & $0.91(0.82-1.00)^{\wedge}$ & & & \\
\hline Education 4 & & & $-0.44(0.17)^{\star \star}$ & \\
\hline \multicolumn{5}{|l|}{ 2. Symptoms } \\
\hline 0 Symptoms & 1 & 1 & & \\
\hline 1 Symptom & $0.63(0.30-1.33)$ & $1.85(0.63-5.40)$ & $-0.48(0.32)$ & $-0.34(0.21)$ \\
\hline$>1$ Symptom & $0.51(0.20-1.29)$ & $1.17(0.44-3.09)$ & $-0.24(0.26)$ & $-0.21(0.26)$ \\
\hline Time & $0.97(0.75-1.26)$ & $1.49(0.94-2.36)^{\wedge}$ & $\wedge-0.35(0.14)^{*}$ & $-0.16(0.08)^{*}$ \\
\hline $\mathrm{Age}^{4}$ & & & $-0.08(0.03)^{\star \star}$ & \\
\hline \multicolumn{5}{|l|}{ 3. Neurological } \\
\hline Kurtzke & $0.72(0.39-1.35)$ & $0.88(0.49-1.61)$ & $-0.26(0.26)$ & $-0.15(0.16)$ \\
\hline Time & $0.93(0.75-1.15)$ & $1.47(1.10-1.95)^{\star}$ & $\star \star-0.41(0.12)^{\star \star \star}$ & $\star-0.18(0.05)^{\star \star *}$ \\
\hline \multicolumn{5}{|c|}{ 4. Neuropsychological } \\
\hline Memory & $0.99(0.94-1.05)$ & $1.02(0.98-1.08)$ & $-0.18(0.13)$ & $-0.00(0.12)$ \\
\hline Time & $0.44(0.33-0.58)$ & $1.56(1.03-2.35)^{\star}$ & ${ }^{\star}-0.43(0.13)^{\star \star \star}$ & $\star-0.20(0.16)^{\star \star \star}$ \\
\hline $\mathrm{Age}^{4}$ & & & $-0.07(0.02)^{\star \star}$ & \\
\hline Education 4 & & & $-0.45(0.18)^{*}$ & \\
\hline \multicolumn{5}{|c|}{ 5. Psychosocial } \\
\hline Depression & $0.51(0.31-0.83)^{\star \star}$ & $1.06(0.68-1.65)$ & $-0.29(0.13)^{\star}$ & $-0.24(0.14)^{\wedge}$ \\
\hline Time & $0.87(0.64-1.18)$ & $1.54(1.04-2.29)^{*}$ & * $-0.42(0.15)^{\star *}$ & $-0.24(0.06)^{\star \star \star *}$ \\
\hline $\mathrm{Age}^{4}$ & $0.92(0.83-1.01)^{\wedge}$ & & $-0.08(0.02)^{*}$ & \\
\hline Education 4 & & & $-0.39(0.17)^{\star}$ & \\
\hline
\end{tabular}

$\wedge=p \leq .10 ; * p \leq .05 ; *=p \leq .01 ; * * * .001$

${ }^{1} 0=$ abstinent $1=$ sexually active

21 = monogamous, $0=$ multiple partners

${ }^{3} \mathrm{Cl}=95 \%$ confidence interval; $\mathrm{B}=$ regression coefficient estimate; s.e. = standard error of the estimate

4 Age and education assessed for all dependent variables but were dropped from the model if not marginally associated $(p \leq .10)$. 
CD4, medical symptoms, Kurtzke neurological impairment, and memory scores were not associated with any of the sexual risk behavior variables. This could indicate that the women engaged in these sexual risk behaviors in spite of increased symptomatology or that reductions in risk behavior were common among the healthier participants as well. Another consideration is the relatively high rate of monogamy among the sexually active women. Sexual behavior may be more stable over time in a primary relationship, even as symptoms develop.

Psychological status appears to be more relevant to the sexual behavior of these women than physiological factors. Women who were abstinent were more likely to score higher on the Depression scale. Having lower frequencies of unprotected sex is also a function of higher Depression scores. Additional analyses (not shown) associating total sex occasions (regardless of condom use) by depressive symptoms produced very similar results as the analysis involving unprotected sex occasions. This indicates that depressive mood is associated with less sexual activity in general, not simply unprotected activity. Diminished interest in sex can be a symptom of depression; on the other hand, the loss or lack of a sexual partner could also result in psychological distress, loneliness, and depressive mood.

Several study limitations should be noted. First, the typical participant is an African-American woman in her late 30s. These women may have quite different patterns of sexual risk behavior than, for example, Latina IDUs in Puerto Rico or younger, white IDUs in Seattle. Second, women who were willing to volunteer for a research project may not be comparable to other segments of the IDU population. Third, participation in this study probably affected the participants' knowledge and behavior. The assessments likely increased participants' self-awareness of their sexual risk behavior and possibly increasing their curiosity about AIDS-related information. We cannot say with certainty that these women would have changed their behavior in similar ways had they not participated in our study. Fourth, these analyses are limited due to the small number of participants and substantial attrition. Nevertheless, it is interesting that reductions in risk behavior were sufficiently large to be detected in spite of the small sample size. Finally, given the focus of the current analyses, changes in injection drug use and the association between drug use and sexual risk behavior were not explored. Given the high rates of drug use in this sample, the prevalence of poly-drug use, high variability in substance use patterns over time, and the various effects of drugs on sexual functioning and behavior based on dosage and dependence/addiction, we determined that these complex associations were beyond the scope of this paper. 
In conclusion, both HIV + and HIV - IDU women have reported reductions in sexual risk behavior. However, unprotected sex was reported by a substantial proportion of the cohort indicating the continued need for intervention. It is also informative that affect status, in this case depressed mood, was more relevant to sexual risk behavior than the other variables assessed. Various other psychiatric/psychologic factors may also be related to sexual risk behavior, such as psychiatric diagnosis (major depression, psychoticism, bipolar disorder), personality disorders (paranoia, obsessive-compulsive disorder, anxiety), and more general personality measures (self-esteem, hopelessness). An exploration of these factors, among HIV - women as well as HIV+, would be useful in understanding risk behavior and its reduction.

\section{REFERENCES}

Battjes, R. J. \& Pickens, R. (1988; June). HIV infection among intravenous drug abusers (IVDAs) in five U.S. cities. Poster session presented at the Fourth International AIDS Conference, Stockholm, Sweden.

Booth, R. E. (1995). Gender differences in high-risk sex behaviors among heterosexual drug injectors and crack smokers. American Journal of Drug and Alcohol Abuse, $21,419-432$.

Booth, R. E., Koester, S. K., \& Pinto, F. (1995). Gender differences in sex-risk behaviors, economic livelihood, and self-concept among drug injectors and crack smokers. The American Journal on Addictions, 4, 313-322.

Booth, R. E. \& Watters, J. K. (1994). How effective are risk-reduction interventions targeting injecting drug users? AIDS, 8, 1515-1524.

Buschke, H. \& Fuld, P. A. (1974). Evaluating storage, retention, and retrieval in disordered memory and learning. Neurology, 24, 1019-1025.

Centers for Disease Control (1986). CDC classification system for human T-lymphotropic virus type IIl/lymphadenopathy-associated virus infections. Morbidity and Mortality Weekly Report, 35, 334-339.

Davies, A. G., Dominy, N. J., Peters, A. D., \& Richardson, A. M. (1996). Gender differences in HIV risk behavior of injecting drug users in Edinburgh. AIDS Care, 8, 517-527.

Deren, S., Rees, D. W., Beardsley, M., \& Tortu, S. et al. (1995). Outcomes of a risk-reduction intervention with high-risk populations: the Harlem AIDS project. AIDS Education and Prevention, 7, 379-390.

Derogatis, L. R., Lipman, R. S., \& Covil, L. (1973). SCL-90: an outpatient psychiatric rating scale-preliminary report. Psychopharmacology Bulletin, 9, 13-28.

Des Jarlais, D. C., Friedman, S. R., Choopanya, K., Vanichseni, S., \& Ward, T. P. (1992). International epidemiology of HIV and AIDS among injecting drug users. $A I D S, 6,1053-1068$.

Des Jarlais, D. C., Friedman, S. R., Friedmann, P., Wenston, J., Sotheran, J. L., Choopanya, K., Vanichseni, S., Raktham, S., Goldberg, D., Frischer, M., 
Green, S., Lima, E. S, Bastos, F. I., \& Telles, P. R. (1995). HIV/AIDS-related behavior change among injecting drug users in different national settings. AIDS, 9, 611-617.

Dolezal, C., Meyer-Bahlburg, H. F. L., Liu, X., Ehrhardı, A. A., Exner, T. M., Rabkin, J. G., Gorman, J. M., Marder, K., \& Stern, Y. (1997). Longitudinal changes in sexual risk behavior among HIV+ and HIV- male injecting drug users. The American Journal of Drug and Alcohol Abuse (in press).

Dwyer, R., Richardson, D., Ross, M. W., Wodak, A., Miller, M. E., \& Gold, J. (1994). A comparison of HIV risk between women and men who inject drugs. AIDS Education and Prevention, 6, 379-389.

Ehrhardt, A. A., Nöstlinger, C., Meyer-Bahlburg, H. F. L., Exner, T. M., Gruen, R. S., Yingling, S. L., Gorman, J. M., El-Sadr, W., \& Sorrell, S. J. (1995). Sexual risk behavior among women with injected drug use histories. Journal of Psychology \& Human Sexuality, 7, 99-119.

El-Sadr, W., Goetz, R. R., Sorrell, S., Joseph, M., Ehrhardt, A., \& Gorman, J. M. (1992). Clinical and laboratory correlates of human immunodeficiency virus infection in a cohort of intravenous drug users from New York, NY. Archives of Internal Medicine, 152, 1653-1659.

Exner, T. M., Meyer-Bahlburg, H. F. L., Dolezal, C. L., Liu, X., Ehrhardt, A. A., Gorman, J. M., Marder, K., Rabkin, J. G., \& Stern, Y. (1997). Gay men`s sexual risk behavior changes over 5 years. (Unpublished manuscript).

Exner, T. M., Seal, D. W., \& Ehrhardt, A. A. (1997). A review of HIV interventions for at-risk women. AIDS and Behavior, 1(2), 93-124.

Fisher, J. D., \& Fisher, W. A. (1992). Changing AIDS-risk behavior. Psychological Bulletin, 111, 455-474.

Freeman, R. C., Rodriguez, G. M., \& French, J. F. (1994). A comparison of male and female intravenous drug users' risk behaviors for HIV infection. American Journal of Drug and Alcohol Abuse, 20, 129-157.

Friedman, S. R., Jose, B., Neaigus, A., Goldstein, M., Curtis, R., Ildefonso, G., Mota, P., \& Des Jarlais, D. C. (1994). Consistent condom use in relationships between seropositive injecting drug users and sex partners who do not inject drugs. ADS , 8, 357-36i.

Gruen, R. S., \& Meyer-Bahlburg, H. F. L. (1992). Training Manual for Research Interviews about Sexual Behavior. Unpublished manuscript (available from 2nd author).

Iguchi, M. Y., Bux, Jr., D. A., Lidz, V., French, J. F., Baxter, R. C., \& Platt, J. J. (1996). Changes in HIV risk behavior among injecting drug users: the impact of 21 versus 90 days of methadone detoxification. AIDS, 10, 1719-1728.

Joseph, J. G., Montgomery, S., Kessler, R., Ostrow, D. G., Emmons, C. A., \& Phair, J. P. (1987). Two-year longitudinal study of behavioral risk reduction in a cohort of homosexual men. Poster session presented at the Third International Conference on AIDS, Washington, D. C.

Kleinman, P. H., Friedman, S. R., Goldsmith, D. S., Mauge, C. E., \& Des Jarlais, D. C. (1988, June). HIV seropositivity in a population of street intravenous 
drug users in New York City in 1987. Poster session presented at the Fourth International AIDS Conference, Stockholm, Sweden.

Kurtzke, J. F. (1983). Rating neurologic impairment in multiple sclerosis: an expanded disability status scale (EDSS). Netrology, 33, 1444-1452.

Liang, K. Y. \& Zeger, S. L. (1986). Longitudinal data analysis using generalized linear models. Biometrika, 73, 13-22.

Lipsitz, J. D., Williams, J. B. W., Rabkin, J. G., Remien, R. H., Bradbury, M., el Sadr, W., Goetz, R., Sorrell, S., \& Gorman, J. (1994). Psychopathology in male and female intravenous drug users with and without HIV infection. American Journal of Psychiatry, 151, 1662-1668.

Marder, K., Liu, X., Stern, Y., Malouf, R., Dooneief, G., Bell, K., Todak, G., Joseph, M., Sorrell, S., EJ Sadr, W., Williams, J. B. W., Ehrhardt, A., Stein, Z., \& Gorman, J. (1995). Risk of human immunodeficiency virus type 1-related neurologic disease in a cohort of intravenous drug users. Archives of Neurology, 52, 1174-1182.

Meyer-Bahlburg, H. F. L., Ehrhardt, A. A., Exner, T. M., Calderwood, M., \& Gruen, R. S. (1988). Sexual Risk Behavior Assessment Schedule-Adult-IDU Women, Baseline (SERBAS-A-DF-1). Unpublished. Columbia University, Department of Psychiatry, New York.

Nemoto, T., Foster, K., \& Brown, L. (1991). Effect of psychological factors on risk behavior of human immunodeficiency virus (HIV) infection among intravenous drug users (IVDUs). The International Jounnal of the Addictions, 26 , 441-456.

New York City Department of Health. (1988). AIDS Surveillance Update, December 28, 1988. New York, NY: Author.

Nicolosi, A., Corred-Leite, M. L., Musicco, M., Arici, C., Gavazzeni, G., \& Lazzarin, A. (1994). The efficiency of male-to-female and female-to-male sexual transmission of the human immunodeficiency virus: a study of 730 stable couples. Epidemiology, 5, 570-575.

O'Leary, A. \& Jemmott, L. S. (1995). General issues in the prevention of AIDS in women. In A. O'Leary \& L. S. Jemmoth (Eds.), Women at Risk: Issues in the Primary Prevention of AIDS (pp. 175-193). New York: Plenum Press.

Ostrow, D. G. (1989). Risk reduction for transmission of Human Immunodeficiency Virus in high-risk communities. Psychiatric Medicine, 7, 79-96.

Rabkin, J. G., Johnson, J., Lin, S-H., Lipsitz, J. D., Remien, R. H., Williams, J. B. W., \& Gorman, J. M. (1997). Psychopathology in male and female HIV-positive and negative injecting drug users: longitudinal course over 3 years. AIDS, $11,507-515$.

Rietmeijer, C. A., Kane, M. S., Simons, P. Z., Corby, N. H., Wolitski, R. J., Higgins, D. L., Judson, F. N., \& Cohn, D. L. (1996). Increasing use of bleach and condoms among injecting drug users in Denver: outcome of a targeted community-level HIV prevention program. AIDS, 10, 291-298.

Schilling, R. F., El-Bassel, N., \& Gilbert, L. (1993). Predictors of changes in sexual behavior among women on methadone. The American Journal of Drug and Alcohol Abuse, 19, 409-422. 
Schoenbaum, E. E., Selwyn, P. A., Hartel, D., \& Friedland, G. H. (1988, June). HIV infection in intravenous drug users in New York City: the relation of drug use and heterosexual behaviors and race/ethnicity. Poster session presented at the Fourth International AIDS Conference, Stockholm, Sweden.

Stern, Y., Liu, X., Marder, K., Todak, G., Sano, M., Malouf, R., Joseph, M., El Sadr, W., Ehrhardt, A., Williams, J. B. W., \& Gorman, J. (1996). Neuropsychological changes in a prospectively followed cohort of intravenous drug users with and without HIV.

Vanichseni, S., Des Jarlais, D. C., Choopanya, K., Friedmann, P., Wenston, J., Sonchai, W., Sotheran, J. L., Raktham, S., Carballo, M., \& Friedman, S. R. (1993). Condom use with primary partners among injecting drug users in Bangkok, Thailand and New York City, United States. AIDS, 7, 887-891.

Watkins, K. E., Metzger, D., Woody, G. E., \& McLellan, A. T. et al. (1993). Determinants of condom use among intravenous drug users. AIDS, 7, 719-723.

Weissman, G. \& Brown, V. (1995). Drug-using women and HIV. In A. O'Leary \& L. S. Jemmoth (Eds.), Women at Risk: Issues in the Primary Prevention of AIDS (pp. 175-193). New York: Plenum Press.

Wolitski, R. J., Fishbein, M., Johnson, W. D., Schnell, D. J., \& Esacove, A. (1996). Sources of HIV information among injecting drug users: association with gender, ethnicity, and risk behavior. AIDS Community Demonstration Projects. AIDS Care, 8, 541-555. 